\title{
JOB SATISFACTION AMONG NURSES IN PUBLIC AND PRIVATE HOSPITALS OF RAWALPINDI AND ISLAMABAD
}

\author{
Saman Waqar', Saima Hamid ${ }^{2}$ \\ ${ }^{1}$ PhD Fellow, Health Services Academy, Islamabad. ${ }^{2}$ Associates Professor, Health Services Academy, Islamabad. \\ ${ }^{1}$ Corresponding Author: PhD Fellow, Health Services Academy, Islamabad. Email: saman.naqvi@yahoo.com
}

\begin{abstract}
Background: Job satisfaction is an important factor for retention of health workers within organization. Multiple factors have influenced the job satisfaction among nurses working in the public sector hospitals of Pakistan. This study was conducted to quantify and compare the levels of job satisfaction among nurses of tertiary care public and private hospitals.

Methods: Across sectional comparative study was conducted in one Public and one Private hospital in Rawalpindi and Islamabad over the period of 6 months. The study included all nurses registered with Pakistan Nursing Council (PNC). Sampling was done by first acquiring the list of all the hospitals from Rawalpindi and Islamabad, 2 hospitals were then selected. Afterwards, the list of all the registered nurses was taken; sample size was determined by applying inclusion / exclusion criteria and by simple random technique by computer generated method. Data was analyzed by using SSS.

Results: Results showed that working conditions were more comfortable and working relations with male coworkers were friendlier in private hospital as compared to public hospitals. Satisfaction with the competence of senior nurses, and administrative support in service problems was also more in private hospital. Majority of public hospital nurses were satisfied with their profession because of manageable duty hours, pay and other benefits provided and administrative support in their domestic problems. On the other hand private hospital nurses were more satisfied with positive feedback of their performance, professional growth, and promotion system.

Conclusion: There is a dire need to improve the conditions regarding working schedule, working environment and management support of nursing staff of hospitals in Pakistan.

Key words: Job satisfaction, nurses, nursing experience, sociocultural aspects.

\section{Introduction:}

Introduction: Nurse means to treat with care1. WHO has defined a nurse as a person who has basic qualification in nursing education and practices nursing in their area (1). A qualified nurse offers nursing care for promotion of health and illness prevention (2). They form a significant connection between the patient and the doctor by providing the healthcare and reducing the communication gap between the patient and the doctor (3). For the health system to work appropriately, nurses have to be motivated, which is directly associated with their job satisfaction (4). Job satisfaction is an enjoyable emotional condition resulting from appraisal of one's job experience (5). Features influencing job satisfaction are type of job, salary, promotion, management, and working circumstances (6). A well-organized organization usually sees a worker as a main source of quality and productivity (7). In Pakistan, work overload is causing dissatisfaction among nurses resulting in poor quality of patient care and poor performing health system. In addition, professional, financial insufficiencies as well as attitude of colleagues are the

major factors leading to dissatisfaction of nursing work force. By addressing these issues, satisfaction of nursing staff can be improved and will attract more competent people in this profession (5). The aim of this study is to address the problems faced by nurses so a timely action can be taken for their solution.

Methodology: Study was conducted in public and private tertiary care hospital of Rawalpindi and Islamabad over a period of 6 months. The study design was comparative cross-sectional and intended to quantify the proportion of nurses satisfied with their job and to compare this proportion between the public and private sector. The hypothesis thus formulated was tested at Alpha $=0.05$ (significance level), the power of the study was kept at $80 \%$. The anticipated population proportion for the public sector nurses was set at 0.50 whereas the same was kept at 0.65 for the private sector (8). A difference of $15 \%$ was expected in the satisfaction level of public and private hospitals. Minimum sample size for the study was calculated using sample size calculation software by $\mathrm{WHO}$ and for each group of nurses was 76 (9). Simple Random Sampling from
\end{abstract}


among the two major public and private sector tertiary care hospitals of Rawalpindi and Islamabad was done. All the nurses of the selected public and private tertiary care hospitals who were registered with PNC were included in the study. Nurses who were either not registered or had an expired registration were excluded from the study and so were Paramedics, other allied health care professionals and nurses with a job experience (in present) position of 1 year or less. Two major tertiary care hospitals were selected for the conduct of the study, one each from the Public and the Private sector. Selection of these hospitals from all of the hospitals of the twin cities was made, based on an assumption that these two would be the best representative of the targeted population. Upon the grant of organizational consent, lists of all the employed nursing personnel were obtained. A sampling frame was created and adequate sample size was calculated. The sampling frame consisted of 1154 individuals; a list of 152 random numbers was generated using computer software Microsoft Excel 2003. These 152 individuals were all included in the sample. Out of 152 respondents, 76 respondents were from public hospitals and 76 from a private hospital.

Each independent respondent was approached and a formal written consent was obtained after having adequately explained the objectives and the rationale for the study. A structured questionnaire was administered with first section containing demographic variables like age, marital status, number of service years, qualification. The questionnaire was prepared keeping in mind all the possible factors affecting job satisfaction of nurses. It mainly covered 3 basic areas of working environment, working schedule and management support affecting job satisfaction of nurses. All the questions in the questionnaire were closed ended and their responses were based on Likert scale, 9 which was modified for certain questions depending on the desired targeted information. These responses were coded and their coding was used for data entry and generating a satisfaction scores for every individual. Certain other questions which had dichotomous responses did not contribute to the satisfaction score. The questionnaire was administered and filled by the primary researcher alone. It was developed in English however at the time of interviewing the respondents; their queries were explained in Urdu as well. The order of responses to the questions contributing to the final satisfaction score was meticulously looked into; ensuring that positive response to every question scores the highest in each category. SPSS-15 software was used to analyze the data.

Results:

There were 144 females and 8 male respondents. Minimum age of the respondents was 20 and maximum was 50 with a mean age of 36 . There were 108 staff nurses, 41 head nurses and 3 nursing superintendents.
There were 43 matriculated, $57 \mathrm{FA} / \mathrm{FSc}, 49 \mathrm{BA} / \mathrm{BSc}$ and $3 \mathrm{MA} / \mathrm{MPhil}$ nurses. 138 were married and 14 were unmarried (Figure 1). Range of number of service years was between 1 and 33 with a mean of 13 . Salary of the nurses was between 9000 and 44000 with a median of 17000. Chi square was applied to see the proportion of nurses satisfied in their work schedule, working environment and management support.it is important to note that a greater proportion of public sector nurses were more satisfied (89.5\%) as compared to private sector $(75 \%), x 2(1, n=152)=5.449, p=0.001$ (Figure 2). As far as the satisfaction with promotion system is concerned, proportion of nurses in private sector $(78.9 \%)$ were more satisfied as compared to public sector $(60 \%), x 2(1, n=152)=6.110, p=0.022$. Results of administrative support in service problems showed that private sector nurses were more satisfied $(98.7 \%)$ as compare to public sector nurses $(85.5 \%), \times 2(1, n=152)$ $=9.048, p=0.007$. Regarding managing kids with the job, proportion of public sector nurses were more satisfied $(100 \%)$ as compared to private sector nurses $(88.2 \%)$, $x 2(1)=8.621, p<0.05$ (Table 1$)$.

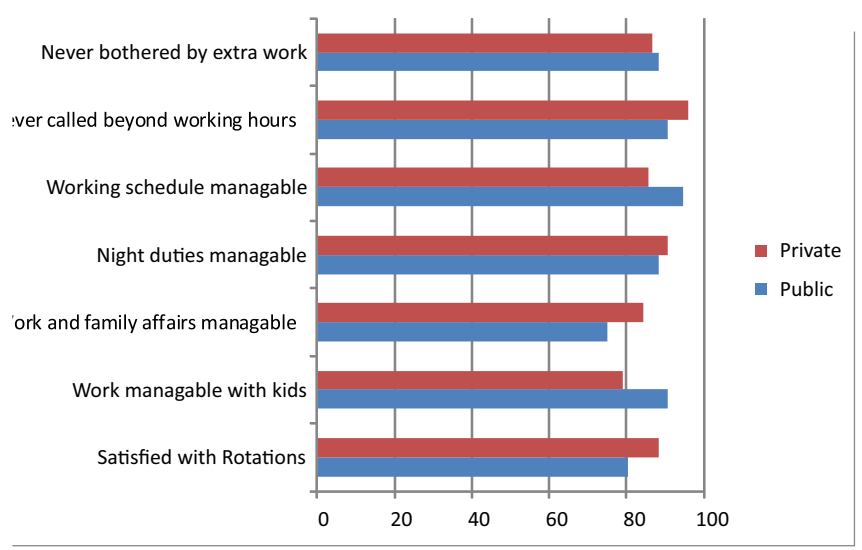

Figure:1 Percentages of the responses regarding working schedule of the respondents in Public and Private hospitals 
Figure:2 Percentages of the job satisfaction regarding management support in Public and Private hospitals

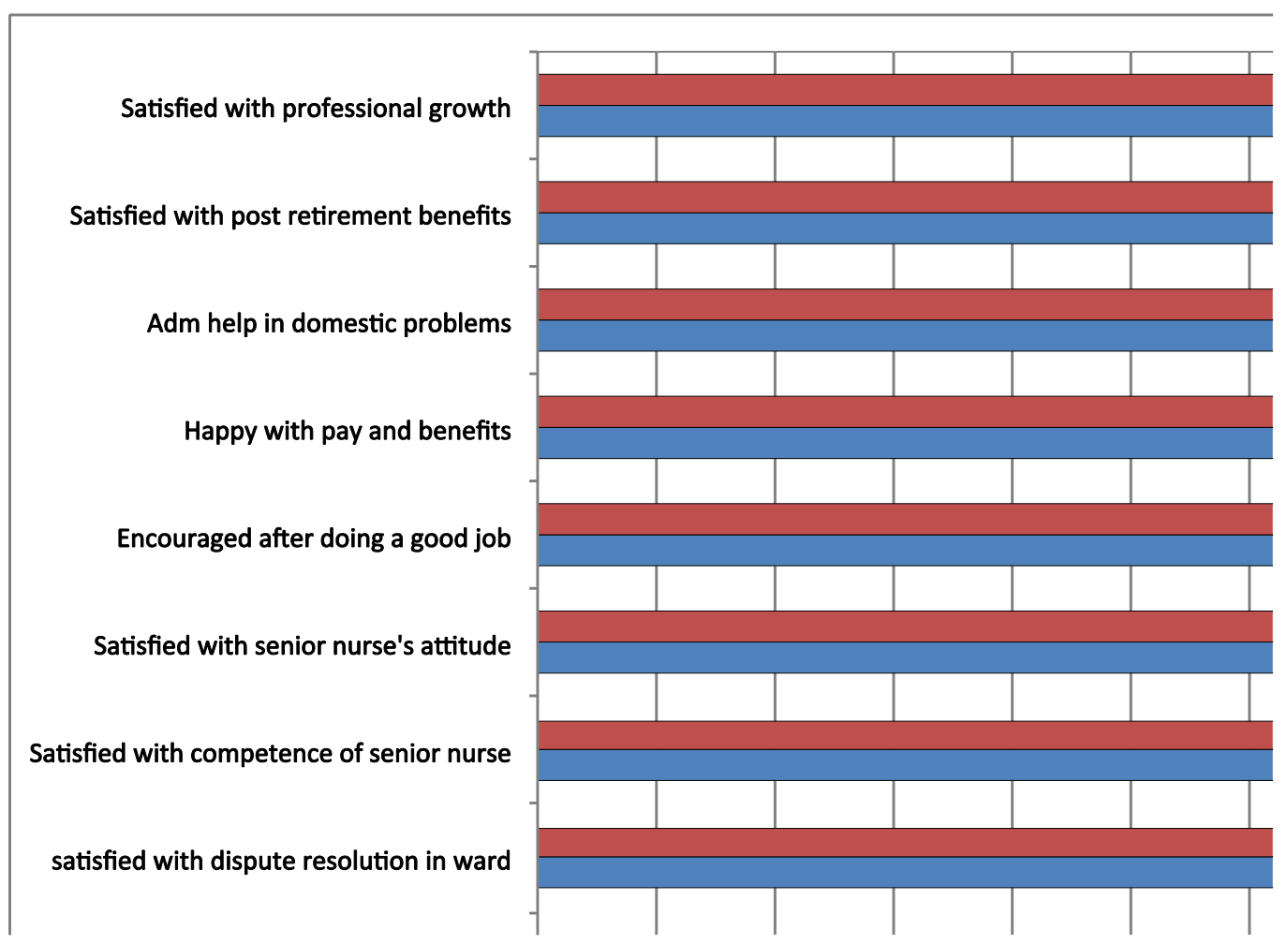

Table:1 Frequencies and percentages of the responses regarding working environment in Public and Private Hospitals

\begin{tabular}{|c|c|c|c|c|c|c|c|}
\hline \multirow[t]{2}{*}{ S.N } & \multirow[t]{2}{*}{ Variables } & \multicolumn{2}{|c|}{ Public } & \multicolumn{2}{|c|}{ Private } & \multicolumn{2}{|c|}{ Total } \\
\hline & & $\mathbf{N}$ & $\%$ & $\mathbf{N}$ & $\%$ & $\mathbf{N}$ & $\%$ \\
\hline 1. & $\begin{array}{l}\text { Working conditions } \\
\text { comfortable }\end{array}$ & 56 & 73.3 & 66 & 86.8 & 122 & 80.3 \\
\hline 2. & $\begin{array}{l}\text { satisfied with } \\
\text { accommodation facilities }\end{array}$ & 48 & 63.2 & 53 & 69.7 & 101 & 66.4 \\
\hline 3. & $\begin{array}{l}\text { Satisfied with the friendly } \\
\text { working relation }\end{array}$ & 76 & 100 & 74 & 97.4 & 150 & 98.7 \\
\hline 4. & $\begin{array}{l}\text { Satisfied with attitude of } \\
\text { male coworkers }\end{array}$ & 68 & 89.5 & 73 & 96.1 & 141 & 92.8 \\
\hline 5. & $\begin{array}{l}\text { Satisfied with the respect } \\
\text { given by the community }\end{array}$ & 62 & 81.6 & 65 & 85.5 & 127 & 83.6 \\
\hline 6. & Satisfied with skill utilization & 76 & 100 & 76 & 100 & 152 & 100 \\
\hline 7. & $\begin{array}{l}\text { Not getting bored with the } \\
\text { same routine }\end{array}$ & 75 & 98.7 & 74 & 97.4 & 149 & 98.5 \\
\hline 8. & $\begin{array}{l}\text { Job providing feeling of } \\
\text { accomplishment }\end{array}$ & 70 & 92.1 & 70 & 92.1 & 140 & 92.1 \\
\hline 9. & $\begin{array}{l}\text { Profession is a major } \\
\text { contributor in improving } \\
\text { health }\end{array}$ & 76 & 100 & 74 & 97.4 & 150 & 98.7 \\
\hline 10. & $\begin{array}{l}\text { Would choose the same } \\
\text { profession again }\end{array}$ & 65 & 85.5 & 64 & 84.2 & 129 & 84.9 \\
\hline
\end{tabular}

\section{Discussion:}

The notion of job satisfaction among nurses is of exceptionally important. Satisfied nurses more likely stay in field of nursing and in the organization in which they are satisfied. Taking into account the considerable nursing deficiency, retention of nursing staff is extremely critical to healthcare industry. Management of the hospitals must be equipped with the information needed to help in creating a place of work that will draw new nurses and retain old ones. Nurses often work in substandard conditions with insufficient staffing and deficiency of necessary supplies. These things, among others, may lead to job dissatisfaction and pushes nurses to find employment somewhere else, frequently outside the field of nursing. This study is an effort to compare the levels of job satisfaction among nurses of public and private institutions. Satisfaction level was high in age group between 34-46 years, mainly because of adjustment to the job and more job prospects; similar results were found in the study in Grafton Base Hospital12 where young age group was less satisfied due to low career opportunities. Another study showed that younger nurses and better educated respondents were more satisfied with their jobs (1). Head nurses and nursing superintendents reported higher satisfaction because of higher pay, more autonomy and experience. Similar results were shown in a study at Sidama (5). Respondents were mostly married (127), some reported difficulty in managing domestic affairs with their jobs and this was very similar to the study conducted in Regional Public Hospital Heti (12). Skill utilization in Private and Public hospitals was same which was were very dissimilar to the study carried out in Islamabad where nurses in the private hospitals were more satisfied with their skill utilization1. Similar results were found in the study carried out in Abbottabad13 where nurses were mostly dissatisfied with poor skill utilization and low salaries. In contrast a study in Cyprus showed that skills 
utilization was the least satisfactory element (4). Working conditions were comparatively better in private hospitals which were similar to the study conducted in Islamabad.1 and at Heti hospital.12 Also study at Abbottabad showed that poor working conditions were among the top dissatisfying factors (13). Nurses in private hospital were more satisfied with training courses compared to public hospitals, similar to studies conducted in Islamabad (1) where the educational opportunities were more in the private hospitals and study in Sidama (5) where most of the respondents were satisfied with their jobs because of in-service education and training. Nurses at Abbottabad were highly dissatisfied with their educational and developmental opportunities (13). Private hospital had more promotion opportunities as compared to public hospitals. Similarly, study conducted in Regional Public Hospital Haiti showed that one of the most dissatisfying factors was poor promotion possibilities. Respondents in private hospital were more satisfied with rotational duties and flexible working schedule as compared to public hospitals. Study conducted in Heti had similar result where nurses working on night duties had a constant sense of being undervalued and less acknowledged (12). However some showed higher level of job satisfaction working on night rotation as they could continue their academic studies. Similarly study in Saudi Arabian hospital also revealed that nurses preferred one shift duty because of social and family obligations and nurses whose shifts changed frequently had adaptation problems (11). More help and support was provided by the administration to the nurses in private as compared to public hospital. Similar results were found in the study conducted in Sidama where non supportive administration is one of the main causes of dissatisfaction.5 Study at Abbottabad showed that the nurses were not involved in decision making 13 and were dissatisfied. Similarly study at Cyprus showed that one of the highest motivators in job is appreciation and administrative support (4). Private hospital nurses were satisfied more regarding feedback of their performance as compared to public hospital. A study conducted at Heti showed that lack of appreciation and incentives lead to demotivation and dissatisfaction among nursing staff.12 Study at Islamabad (1) and Cyprus (4) and at tertiary care hospital Rawalpindi (10) also showed similar results where work recognition was among the highest motivating factors. Dispute resolution due to involvement of senior nurses was much better in public hospital as compared to private hospital. Similar results were found in a study carried out in Tertiary Care hospitals in Islamabad where supportive management and helpful seniors led to job satisfaction (1). Regarding the attitude and competence of senior nurses, respondents in private hospital were much satisfied as compared to public hospitals, results were similar in a study conducted on nurses in Islamabad where private hospital showed better satisfaction with senior's attitude
(1). Private hospital nurses were praised and encouraged more after doing a good job as also seen in study conducted in Islamabad1 and Cyprus (4). Similarly, nurses at Sidama (5) and Abbottabad (13) had a constant sense of being undervalued and not being acknowledged resulting in demotivation and dissatisfaction. Private hospital nurses were less satisfied with their pay as compared to public hospital. Study at Rawalpindi also showed that respondents with better salary packages had more satisfaction levels (10). In contrast, the study at Sidama showed that pay was not among the top factors for job satisfaction (5), and nurses in Regional Public Hospital Haiti were satisfied with even lesser pay as they had more job security as compared to private hospitals (12). Study conducted in Saudi Arabia showed that nurses who worked near their villages were more satisfied. Working schedule and managing kids at home was more in private hospitals as compared to public hospitals. 11 In this study, nurses in public hospitals were more satisfied with the working schedule (94.7\%) and grooming of kids $(90.8 \%)$ as compared to private hospitals $((85.5 \%)$ and $(78.9 \%)$ respectively. Attitude of male coworkers and respect given by the community was much better in private hospital as compared to public hospital, similarly a study at Islamabad showed that no respect was shown by the patients, relatives and the doctors in the public hospitals (1). A study at Cyprus (4) and Rawalpindi (10) showed that social respect is one of the top job satisfaction factors. When asked whether they would choose the same profession again, most of the nurses in public as well as private hospital gave a positive answer. CONCLUSION: This study analyzed job satisfaction among nurses of public and private hospitals. The results of the study revealed that in some aspects, nurses in the private setup had more job satisfaction as compared to nurses of public sector while in others, the case was vice versa. As nursing deficiency continues to worsen, job satisfaction of nurses is of fundamental importance. Nursing administrators should start considering the needs of their employees in any organization and should do everything within their power to meet those requirements. Results of this study should be used to develop policies that could help in improving the conditions leading to nurse's job satisfaction, better patient satisfaction, a decrease in turnover of registered nurses and increased profit for the organization. First limitation of the study is the cross sectional design. Long term follow up studies are needed to explore the relationship between nurses' job satisfaction and practice places and due to the limited time period, the study was conducted only in two hospitals. 


\section{References}

1. Hamid S, Malik AU Kamran I, Ramzan M. Job satisfaction among nurses working in the private and public sectors: a qualitative study in tertiary care hospitals in Pakistan.JMDH.2014 Jan;2014(7):25-35.

2. RP Lephlala, VJ Ehlers, MJ Oosthuizen.Factors influencing nurses 's job satisfaction in selected private hospitals in England.Curationis.2008 Sep;31(3):60-69.2008.

3. Chase LK. Nurse manager competencies. lowa. Dec 2010.

4. Lambrou P, Kontodimopoulos N, Niakas D. Motivation and job satisfaction among medical and nursing staff in a Cyprus public general hospital. Human Resource for Health.2010 Nov; 8:26.

5. Asegid A, Belachew T, Yimam E. Factors influencing job satisfaction and anticipated turnover among nurses in Sidama zone public health facilities. Nursing research and practice.2014 Feb; (2014):26 pages.

6. Tanjeen E. A study on factors affecting job satisfaction of Telecommunication industries in Bangladesh.IOSR-JBM.2013 Mar-Apr;8 (6)80-86.

7. Lashchinger HK, Shamian J, Thomas D. Impact of magnet hospital characteristics on nurses' perception of trust, burnout, quality of care and work satisfaction. Journal of Advanced Nursing 2005; Feb 19(5):209-219.

8. Mrayyan MT, Nurse job satisfaction and retention: comparing public to private hospitals in Jordan. Journal of Nursing management 2005, 13, 40-50.

9. Lwanga SK, Lameshow S. Sample size determination in health studies. A practical manual. Geneva: Geneva WHO; 1991.

10. Lu H, While AE, Barriball KL. Job satisfaction and its related factors: A questionnaire survey of hospital nurses in Mainland China. International Journal of Nursing Studies 2006 July 13; 44(2007):p574-588.

11. sultana A, Riaz R,Mehmood F,Khurshid R.level of job satisfaction among nurses working in tertiary c a r e hos p i t a I s of Rawalpindi.RWJ.(2011);36(2):150-154.

12. Gilani E, Wehady AA. Job satisfaction of female Saudi nurses. International Journal of nursing practice.2006;25(11):121-35. Available, from, http://www.emrowho.int.publications/EMHJ/h tml.Accessed on :2014 May

13. Powell I. Experience of night shift nurses in regional public hospitals. A qualitative case study. June 2011. Northern NSW.

14. Bahalkani HA, Ramesh $K$, Lakho AR, Mahar B, Mazhar SB, Majeed A. Job satisfaction in nurses working in tertiary level health care settings of Islamabad. J Ayub Med Coll Abbottabad.2011 JulSep;23(3):130-3. 